\title{
COMPLETE AMINO ACID SEQUENCE OF THE $\alpha$-AMYLASE/SUBTILISIN INHIBITOR FROM BARLEY
}

\author{
by \\ IB SVENDSEN", JØRN HEJGAARD ${ }^{2)}$ and JOHN MUNDY ${ }^{3)}$ \\ 1) Department of Chemistry, Carisberg Laboratory, \\ Gamle Carlsberg Vej 10, DK-2500 Copenhagen Valby \\ ${ }^{2)}$ Department of Biochemistry and Nutrition, \\ Technical University of Denmark, DK-2800 Lyngby \\ ${ }^{37}$ Department of Biotechnology, Carlsberg Research Laboratory, \\ Gamle Carlsberg Vej 10, DK-2500 Copenhagen Valby
}

Keywords: Soybean trypsin inhibitor (Kunitz), winged bean trypsin inhibitor, homology, protease inhibitor

\begin{abstract}
The complete amino acid sequence of the $\alpha$-amylase/subtilisin inhibitor (BASI) isolated from barley has been determined by Edman degradation using spinning cup as well as gas-phase sequencing. Necessary fragments have been obtained from cleavage with cyanogen bromide, hydroxylamine, formic acid, clostripain, and streptococcal protease V8. The molecule consists of a single peptide chain of 181 residues with two disulphide bonds and with a molecular weight of 19,865 . Homology is demonstrated with other members of the soybean trypsin inhibitor (Kunitz) family of inhibitors.
\end{abstract}

\section{INTRODUCTION}

In a previous publication (19) we have described the purification and partial characterization of an inhibitor from barley which was active against endogenous $\alpha$-amylase 2 as well as against subtilisin. The inhibitor appears to be identical to the subtilisin inhibitor described by Yoshikawa et al. (31). Determination of the 40 $\mathrm{N}$-terminal amino acids of the inhibitor showed that it belongs to a family of protease inhibitors classified as the "Soybean trypsin inhibitor family (Kunitz)" (8).

The dual function as an inhibitor of protease and $\alpha$-amylase has apart from BASI, only been demonstrated for inhibitors isolated from wheat (20) and ragi (Indian finger millet) (4). However, more and more evidence has accumulated showing close relationships between various protease and $\alpha$-amylase inhibitors. Thus, the $\alpha$-amylase/ trypsin inhibitor from ragi (4) is homologous with trypsin inhibitors isolated from corn (17) and barley (23) and with $\alpha$-amylase inhibitors isolated from wheat $(16,22,24)$. Similarly, an $\alpha$-amylase inhibitor isolated from ragi (5) is homologous with a protein from barley having a M.W. of approx. 10.000 , but without any known function $(21,28)$. Finally, it has been shown by BARBER et al. (1) that five homologous proteins

Abbreviations: $\mathrm{BASI}=$ barley amylase/subtilisin inhibitor; $\mathrm{CNBr}-=$ cyanogen bromide-; $\mathrm{HPLC}=$ high performance liquid chromatography; $\mathrm{PTH}=$ phenylthiohydantoin; SBTI = soybean trypsin inhibitor; TFA = trifluoroacetic acid; WBTI = winged bean trypsin inhibitor. 
isolated from barley are either protease inhibitors, $\alpha$-amylase inhibitors or have no known function. These findings clearly suggest a common origin for many protease and $\boldsymbol{\alpha}$-amylase inhibitors. It cannot be excluded that these proteins originally served as storage proteins which later specialized into two different inhibitory functions against hydrolytic enzymes. A similar pattern is seen with ovalbumin and Z-protein from barley both of which have no known biological function, but nontheless are homologous with potent mammalian protease inhibitors such as $\alpha_{1}$-antitrypsin, $\alpha_{1}$-antichymotrypsin and antitrypsin-III (9). A structural relationship between the barley trypsin inhibitor and various storage proteins from cereals (14) and castor-bean ( 25 ) has been demonstrated and a theory of their common evolutionary origin postulated (14). As more and more plant proteins are sequenced, the evolutionary relationship between proteins of different biological functions will be clarified. The complete amino acid sequence of BASI described in the present paper is one such contribution.

\section{MATERIALS AND METHODS}

\subsection{Materials}

Barley $\alpha$-amylase/subtilisin inhibitor (BASI) was isolated from barley as described earlier (19). 2-vinylpyridine was obtained from Janssen, Belgium, cyanogen bromide from Sigma, St. Louis, MO, and hydroxylamine from Merck, Darmstadt, F.R.G. Clostripain was from Sigma, St. Louis, MO, and Streptococcal protease V8 was obtained from Miles, Stoke Podes, U.K. Reagents and solvents used in the sequencers were obtained from Applied Biosystem, Foster City, CA (gas-phase sequencer) or Rathburn, U.K. (Beckman sequencer). All other reagents were analytical grade products and deionized water was used throughout.

\subsection{Methods}

\subsection{1.}

Reduction and treatment with 2-vinyl pyridine was done according to (6). Cleavage with cyanogen bromide was performed in $70 \%$ formic acid or $70 \%$ trifluoroacetic acid overnight in the dark at room temperature. Separation of peptides was accomplished on a Sephadex G50 column $(0.9 \times 115 \mathrm{~cm})$ in $30 \%$ acetic acid at room temperature and a flow rate of $4 \mathrm{ml} \times \mathrm{hr}^{-1}$. The eluate was monitored at $280 \mathrm{~nm}$ and appropriate peaks were pooled and freeze-dried.

\subsection{2.}

Cleavage with hydroxylamine was done according to the method described in ref. (2) and the resulting peptides separated as described above.

\subsection{3.}

Cleavage with clostripain was done as described in ref. (27) in $2 \mathrm{mM}-\mathrm{NH}_{4} \mathrm{HCO}_{3}$ including 3 M-urea. At the beginning of the digestion period the solution was slightly turbid but, at the termination after $16 \mathrm{hrs}$ at $38^{\circ} \mathrm{C}$ with an enzyme:substrate ratio of $1: 30$ the solution was clear. Separation of peptides was performed as above.

\subsection{4}

Cleavage at Asp-Pro bonds was done in $70 \%$ formic acid containing $3 \mathrm{M}$-urea. The solution was left for $36 \mathrm{hrs}$ at $40^{\circ} \mathrm{C}$ and then gel filtered on a Biogel P6 column $(1.5 \times 60 \mathrm{~cm})$ in $30 \%$ acetic acid with a flow rate of $10 \mathrm{ml} \times \mathrm{hr}^{-1}$. The eluate was monitored at $280 \mathrm{~nm}$ and appropriate peaks lyophilized.

\subsection{5.}

Cleavage with streptococcal protease $\mathrm{V} 8$ was done according to ref. (10) in $0.1 \mathrm{~N}-\mathrm{NH}_{4} \mathrm{HCO}_{3}$ containing $3 \mathrm{M}$-urea. The digestion mixture was left overnight at room temperature. The resulting peptides were separated on a Sephadex G50 column $(1.6 \times 85 \mathrm{~cm})$ in $30 \%$ acetic acid.

Further separation of peptide mixtures was made by HPLC in a linear gradient system consisting of A: $0.1 \%$ TFA and B: $0.1 \%$ TFA + $90 \%$ acetonitrile. Flow rate $1 \mathrm{ml} \times \mathrm{min}^{-1}$. 


\subsection{6.}

Acid hydrolyses of peptides were performed in $5.7 \mathrm{M}-\mathrm{HCl}$ in evacuated and sealed tubes at 110 ${ }^{\circ} \mathrm{C}$ for $24 \mathrm{hrs}$. Hydrolysis of BASI was made on duplicate samples for 24, 48, 72 and 96 hours. Amino acid analyses were made on a Durrum amino acid analyzer.

\subsection{7.}

Amino acid sequences were determined in a Beckman sequencer, model $830 \mathrm{~B}$ as previously described (11) or in a gas phase sequencer model 470A from Applied Biosystems according to the specifications given by the company. Conversion was conducted in neat TFA. Identification of PTH-amino acids was made by HPLC as described earlier (26).

\section{RESULTS}

\subsection{N-terminal sequence}

Reduced and ethylpyridinated BASI was sequenced 40 cycles. The result agreed with the $\mathrm{N}$-terminal sequence already published ( 8 ) and two uncertainties about positions 32 and 39 were clarified.

\subsection{Cleavage with cyanogen bromide}

According to the amino acid analysis, BASI contains two Met residues and cleavage with cyanogen bromide thus should give rise to three fragments. Sequence analysis of the reaction mixture showed this to be true. In addition peptides starting with Pro were observed in small quantities probably arising from cleavage of Asp-Pro bonds by the acidic medium used. A cleavage between $\mathrm{Asp}_{2}-\mathrm{Pro}_{3}$ was anticipated from the known $\mathrm{N}$-terminal sequence, but additional cleavage took place as well.

Gel filtration of the mixture of $\mathrm{CNBr}$-fragments on Sephadex G50 gave rise to two major peaks as shown in Figure 1. Sequence determination of peak I gave a sequence, starting at Ala $_{36}$ (Figure 5), which was followed through Phe $_{58}$. The shoulder on the descending limb of peak I contained two peptides which on sequencing began with a Pro. One cleavage took place between $A_{s p_{50}}-P{ }_{51}$. The expected small

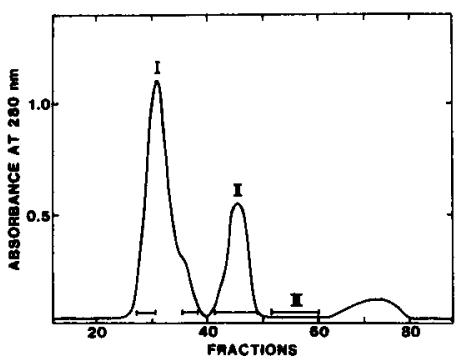

Figure 1. Separation of peptides obtained by cleavage of BASI with cyanogen bromide. Column: Sephadex G $50(0.9 \times 115 \mathrm{~cm})$. Eluant: $30 \%$ acetic acid. Flow rate $4 \mathrm{ml} \times \mathrm{hr}^{-1}$. Fractions pooled as indicated by bars.

peptide $\mathrm{Ala}_{36}-\mathrm{Asp}_{50}$ was located on the chromatogram as shown in Figure 1, III. Peak II was a mixture of two peptides. Sequence determination showed one to be the $\mathrm{N}$-terminal and the other to be the C-terminal (since only three $\mathrm{CNBr}$-peptides were generated) starting at $\mathrm{Ser}_{143}$

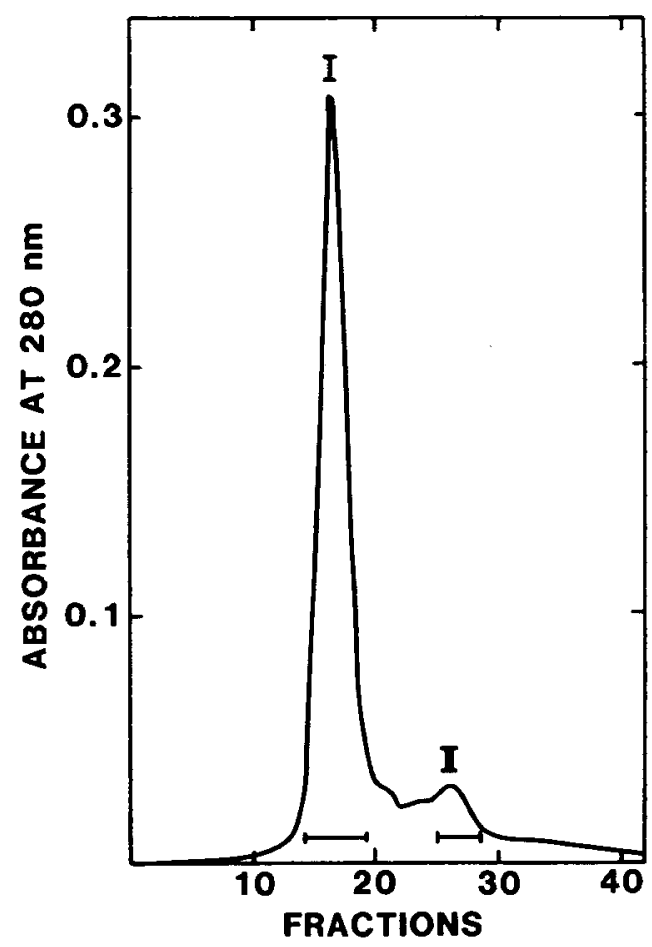

Figure 2. Separation of peptides obtained by cleavage of peak I in Figure 1 with hydroxylamine. Conditions as in Figure 1. 


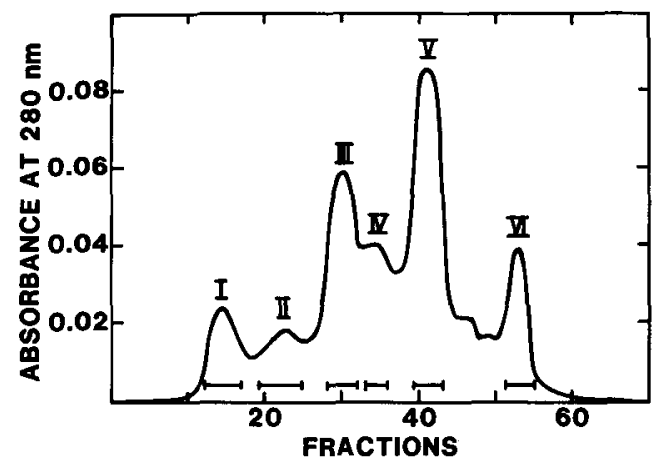

Figure 3. Separation of peptides obtained by cleavage of peak $I$ in Figure 1 with clostripain. Conditions as in Figure 1.

in Figure 5. The two peptides were separated by HPLC and the C-terminal peptide sequenced through $\mathrm{Tyr}_{170}$.

\subsection{Cleavage with hydroxylamine}

Since an Asn-Gly bond was found between position 52 and 53 (Figure 5), the large CNBrfragment (Peak I, Figure 1) was treated with hydroxylamine and gel filtered on a Biogel P6 column (Figure 2). The front peak was the expected peptide starting at Gly $_{53}$ and it was sequenced 36 cycles through $\mathrm{Thr}_{88}$ (Figure 5).

\subsection{Cleavage with clostripain}

The large CNBr-fragment (Peak I, Figure 1) was cleaved with clostripain and the resulting peptides separated on a Sephadex G50 column. The resulting peaks are shown in Figure 3. Sequencing showed that Peak $\mathrm{V}$ contained two peptides; one was the known N-terminal of the $\mathrm{CNBr}$-peptide while the other started at $\mathrm{Ala}_{86}$ (Figure 5) and was sequenced through $\mathrm{Arg}_{106}$. Two additional peptides contained in peak VI providing necessary overlaps were purified by HPLC and sequenced. One started at $\mathrm{His}_{108}$ and continued through Pro $_{119}$ (Figure 5) and another started at $\mathrm{Ile}_{128}$ and was sequenced through Leu $_{141}$.

Cleavage of the C-terminal CNBr-fragment with clostripain generated two peptides which

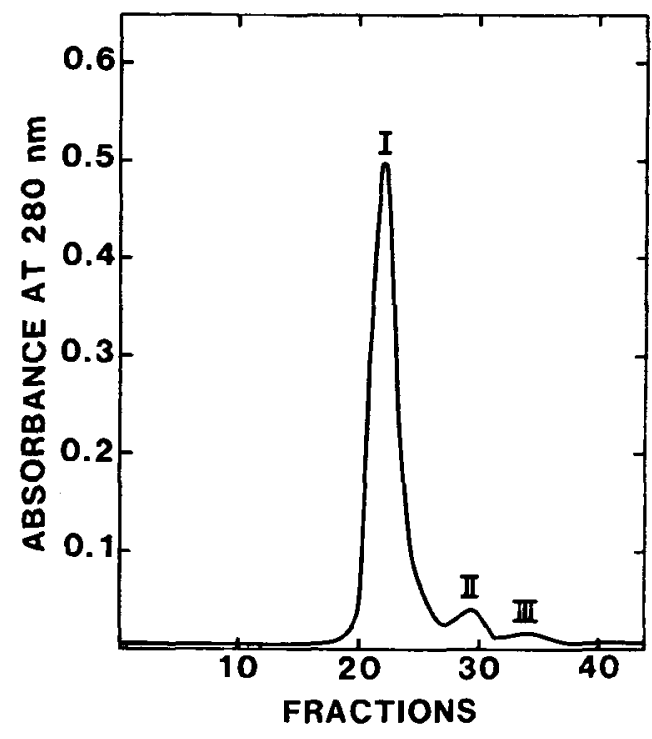

Figure 4. Separation of peptides obtained by cleavage of peak $I$ in Figure 1 with $70 \%$ formic acid. Column: Biogel P6 $(1.5 \times 60 \mathrm{~cm})$. Eluant: $30 \%$ acetic acid. Flow-rate $10 \mathrm{ml}^{\circ} \mathrm{hr}^{-1}$.

were shown by sequencing to be the expected $\mathrm{N}$-terminal starting at $\mathrm{Ser}_{143}$ and a peptide starting at $\mathrm{Asp}_{156}$ (Figure 5). These were sequenced together. The N-terminal peptide disappeared after step 12 while the second peptide was sequenced through Pro ${ }_{\text {s80. }}$.

\subsection{Specific cleavage at Asp-Pro bonds}

Cleavage of BASI with cyanogen bromide in $70 \%$ formic acid gave rise to minor amounts of peptides derived from cleavage between Asp and Pro (section 3.2). Specific cleavage of the large $\mathrm{CNBr}$ fragment at Asp-Pro was conducted (section 2.2.4) and two pure peptides were isolated by gel filtration on Biogel P6 (Figure 4). One was the peptide $\mathrm{Ala}_{36}-\mathrm{Asp}_{50}$ (Figure 4, III). The other peptide (Figure 4, II) started at $\mathrm{Pro}_{11}$ and was sequenced 20 cycles through $\mathrm{Val}_{136}$ (see Figure 5).

\subsection{Cleavage with streptococcal protease V8}

Native BASI was digested with streptococcal protease V8 followed by gel filtration on Sepha- 
Pro-Asn-Gly-Gln-His-Asp-Giy-Phe-Pro-Vai-Arg-Ile-Thr-Pro-Tyr-Gly-Val-Ala-Pro-Ser-Asp-Lys-Ile-Ile-Arg

$80 \quad 90 \quad 100$ 80

Glu-Leu-Ala-Ala-Gly-Arg-Arg-His-Val-Ile-Thr-Gly-Pro-Val-Lys-Asp-Pro-Ser-Pro-Ser-Gly-Arg-Glu-Asn-Ala

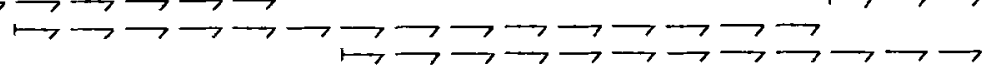

130

Phe-Arg-Ile-Glu-Lys-Tyr-His-Gly-Ala-Glu-Val (Ser)Glu-Tyr-Lys-LeU-Met-Ser-Cys-Gly-Asp-Trp-Cys-Gln-Asp

Leu-Gly-Val-Phe-Arg-Asp-Leu-Lys-Gly-Gly-Ala-Trp-Phe-Leu-Gly-Ala-Thr-Glu-Pro-Tyr-His-Val-Val-Val-Phe

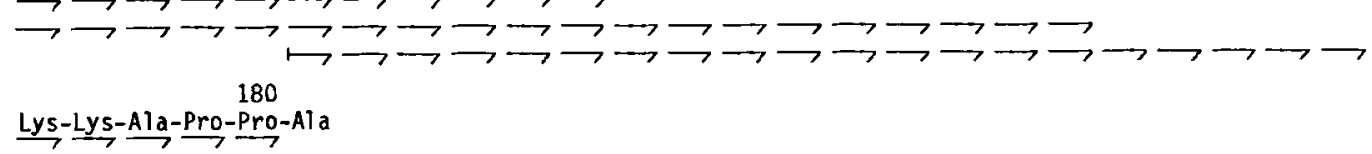

Figure 5. Amino acid sequence of barley amylase/subtilisin inhibitor (BASI). $\vdash$ indicates start and direction of sequencing. The two disulphide bonds $\mathrm{Cys}_{144}-\mathrm{Cys}_{148}$ and $\mathrm{Cys}_{43}-\mathrm{Cys}_{93}$ not shown. For details see text.

dex G50. Peak IV of the resulting chromatogram contained the two peptides which were necessary for completion of the sequence. One peptide started at $\mathrm{Leu}_{102}$ (Figure 5) and was sequenced 15 cycles providing the overlap between two peptides $\left(\mathrm{Ala}_{86}-\mathrm{Arg}_{106}\right.$ and $\mathrm{His}_{108}$. $\operatorname{Arg}_{122}$ ) obtained by cleavage with clostripain. The second peptide started at $\mathrm{Tyr}_{139}$ and was sequenced through $\mathrm{Ala}_{161}$. This peptide connected a clostripain peptide, Ile $_{128}-$ Met $_{142}$, to the C-terminal CNBr-fragment (Figure 5).

Figure 5 shows the completed sequence of BASI based on the peptides described above. In order to simplify the presentation several confirmative sequences have been omitted from the figure. The Ser in position 137, has not been observed directly, but is inserted on the basis of amino acid analysis of the peptide $\mathrm{Ile}_{128}-\mathrm{Met}_{142}$. Finally, the C-terminal residue $\mathrm{Ala}_{181}$ has also been assigned on the basis of amino acid analysis of the C-terminal $\mathrm{CNBr}$-fragment. Attempts to determine the $\mathrm{C}$-terminal residue(s) by cleavage with carboxypeptidase $Y$ have not been successful but YosHIKAWA et al. (31) also found Ala as the C-terminal residue by carboxypeptidase digestion or hydrazinolysis.

No direct attempt has been made to determine the two disulphide bonds in BASI. The assignment is made on the basis of the following observation: If native BASI with intact disulfide bonds is cleaved with cyanogen bromide and the resulting mixture of peptides is gel filtered on Sephadex G50, the C-terminal cyanogen bromide fragment separates from the largest fragment. Both fragments contain two Cys. If disulfide bonds existed between the cysteins from the two peptides these would not separate upon gel filtration. Thus, a disulfide bond must exist between $\mathrm{Cys}_{144}$ and $\mathrm{Cys}_{148}$ and between $\mathrm{Cys}_{43}$ and Cys $_{90}$. 


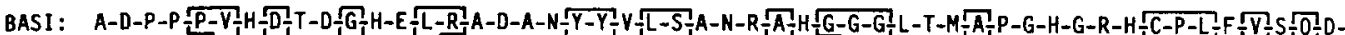

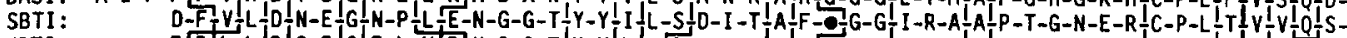

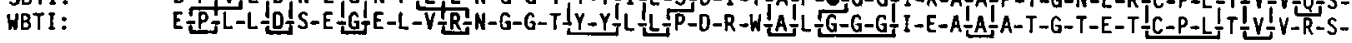

BAS. 6000000

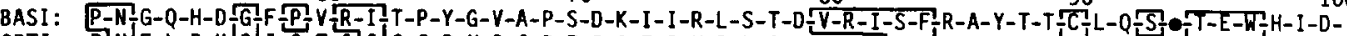

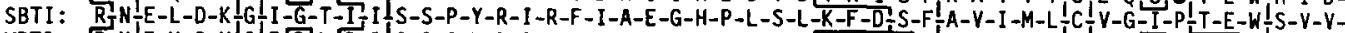
WBTI: P-N-E-V-S-V]G

BASI: $5-120 \quad 130 \quad 140 \quad 150$

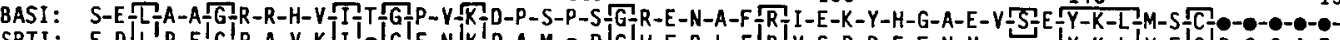

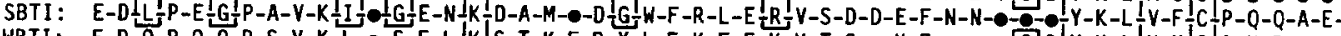

WBTI: $\quad E-D-Q-P-Q-Q-P-S-V-K-L-\bullet-S-E-L-K, S-T-K-F-D-Y-L-F-K-F-E-K-V-T-S-\bullet-K-F-\bullet-\bullet-\oplus-S-S-Y-K-L-K-Y-C-A-K-R-\bullet-\bullet-$

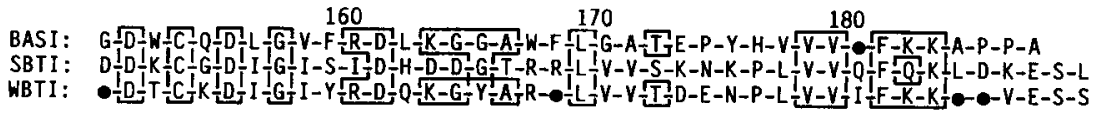

Figure 6. Comparison of the amino acid sequence of barley amylase/subtilisin inhibitor (BASI) with those of soybean trypsin inhibitor (SBTI) (13) and winged bean trypsin inhibitor (WBTI) (30). • indicates gaps introduced in order to maximize homology. Positions which are identical for BASI and one or both of the other inhibitors are boxed. The numbering in this figure deviates from that in Figure 5 due to introduction of gaps.

On the basis of the completed amino acid sequence the molecular weight of BASI is calculated to be 19,865 .

\section{DISCUSSION}

Sequence homology among the $40 \mathrm{~N}$-terminal amino acids has shown that the $\alpha$-amylase/subtilisin inhibitor isolated from barley belongs to the soybean trypsin inhibitor (Kunitz) family of protease inhibitors (8). The completion of the amino acid sequence of BASI now permits a comparison of the entire molecule with that of the soybean trypsin inhibitor and of two closely related winged bean trypsin inhibitors (30) of which only one is included here (Figure 6). The soybean trypsin inhibitor has recently been shown to consist of three genetic variants (12); only the sequence of the originally published inhibitor $\mathrm{Ti}^{\mathrm{a}}(13)$ is included here. The homology between BASI and the two other inhibitors extends throughout the molecule. In order to maximize the homologies several gaps have been introduced. Particularly, the sequence from position 130 to 151 appears to vary in the three inhibitors except for the sequence
$\mathrm{Tyr}_{140}$ to $\mathrm{Cys}_{145}$ which fixes the alignment in this part of the sequences. As presented in Figure 6, $26 \%$ of the residues in BASI and SBTI and $27 \%$ in BASI and WBTI are identical. As expected the homology is closer between SBTI and WBTI ( $45 \%$ identical residues). If the homology is extended also to permit mutation of one base per triplet in the genetic code, an even closer fit is observed: BASI/SBTI 59\%, BASI/WBTI 58\%, SBTI/WBTI 74\%. A database search using the National Biomedical Research Foundations database revealed the expected homologies to SBTI and WBTI, but only fragmentary homologies to other proteins.

Prediction of the secondary structure by the method of GARNIER et al. (7) suggested that BASI contains $\alpha$-helix as well as $\beta$-structure. Four segments of $\alpha$-helix: ${ }^{\text {A) }} \mathrm{Gly}_{11}-\mathrm{Asn}_{19}{ }^{\text {B) }}{ }^{\text {B) }} \mathrm{Asp}_{100^{-}}$ $\operatorname{Arg}_{107},{ }^{C} \mathrm{Glu}_{124}-\mathrm{Lys}_{131}$, and ${ }^{\mathrm{D})} \mathrm{Ala}_{135}-\mathrm{Leu}_{142}$ (Figure 6) are predicted. In contrast SBTI, for which the tertiary structure is known (29), does not contain any $\alpha$-helixes and $\alpha$-helixes are predicted not to occur in WBTI (30). The predicted helixes B) and $C$ ) in BASI partly overlap sequences in the SBTI which cannot be clearly seen from the $\mathrm{x}$-ray diffraction data and $\alpha$-helix D) is located in 
a segment which for the most part, $\mathrm{Val}_{137}-\mathrm{Glu}_{139}$, does not exist in SBTI. The loop between $\mathrm{Cys}_{145}$ and Cys $_{154}$ (Figure 5) is larger in SBTI than in both BASI and WBTI.

Several but not all of the turns between $\beta$-segments seen in SBTI are predicted also in BASI. Thus, although many similarities between the predicted secondary structure of BASI and SBTI exist it also appears that the two structures are not superimposable.

It has not yet been possible to identify the active (or inhibitory) sites in BASI. If the analogy with SBTI holds the primary active site for inhibition of proteases should be located between $\mathrm{Val}_{67}$ and $\mathrm{Ala}_{68}$ (Figure 6) which is compatible with the specificity requirements of the subtilisins but cleavage of this bond has not been demonstrated. The segment around this bond is predicted to be part of an external loop as seen with SBTI and therefore compatible with a probable function as inhibitory site. That BASI does not inhibit trypsin (19) is also compatible with the exchange of an Arg in the primary inhibitory site of SBTI with a Val in BASI. Although SBTI does not inhibit the subtilisins it is cleaved specifically by these proteases between Met $_{88}$-Leu $_{89}$ (Figure 6) (15). In BASI the corresponding bond is between $\mathrm{Thr}_{88}-\mathrm{Thr}_{89}$ (Figure 6), which meets the specificity requirements of the subtilisins better than $\mathrm{Val}_{67}-\mathrm{Ala}_{68}$ (Figure 6). It has been shown that SBTI contains two binding sites for chymotrypsin and trypsin (3) probably including the two bonds mentioned above. Comparable studies has not been performed with BASI, but it is plausible that one or both of the potential corresponding inhibitory sites are functioning in this inhibitor.

No suggestions with respect to the location of the $\alpha$-amylase inhibitory site is available except that it must be located quite a distance from the protease inhibitory site(s) since the two functions are carried out independently (19). Thus, protease inhibition is not inhibited in the presence of $\alpha$-amylase and $\alpha$-amylase inhibition is not inhibited by the presence of protease.

\section{ACKNOWLEDGEMENTS}

Dr. FLEMMING POULSEN is thanked for performing the data base analysis of homologies and secondary structure prediction, and the skilled technical assistance of Mss. BODIL CORNELIUSSEN, LONE SøRENSEN and PIA BREDDAM is gratefully acknowledged.

\section{REFERENCES}

1. Barber, D., R. Sanchez-Monge, E. Mendez, A. LAZARo, F. Garcia-OlmEdo \& G. SAlCEDO: New $\alpha$-amylase and trypsin inhibitors among the CMproteins of barley (Hordeum vulgare). Biochim. Biophys. Acta 869, 115-118 (1986)

2. Bornstein, P. \& G. Balian: Cleavage at Asn-Gly bonds with hydroxylamine. Meth. Enzymol. 47, 132-147 (1977)

3. Bösterling, B. \& U. Quast: Soybean trypsin inhibitor is double headed. Biochim. Biophys. Acta 657, 58-72 (1981)

4. CAMPOS, F. A.P. \& M. Richardoson: The complete amino acid sequence of the bifunctional $\alpha$-amylase/trypsin inhibitor from seeds af ragi (Indian finger millet, Eleusine coracana Gaertn). FEBS Lett. 152, 300-303 (1983)

5. CAMPOS, F. A.P. \&M.RICHARDSON: The complete amino acid sequence of the $\alpha$-amylase inhibitor I-2 from seeds af ragi (Indian finger millet, Eleusine coracana Gaertn. ). FEBS Lett. 167, 221-225 (1984)

6. Friedman, M., J. C. Zahnley \& J. R. Wagner: Estimation of the disulfide content of trypsin inhibitors as $\mathrm{S}-\boldsymbol{\beta}$-(2-pyridylethyl)-L-cysteine. Anal. Biochem. 106, 27-24 (1980)

7. Garnier, J., D. J. Osguthorpe \& B. Robson: Analysis of the accuracy and implications of simple methods for predicting the secondary structure of globular proteins. J. Mol. Biol. 120, 97-120 (1978)

8. HejgaArd, J., I. Svendsen \& J. Mundy: Barley $a$-amylase/subtilisin inhibitor. II. N-terminal amino acid sequence and homology with inhibitors of the soybean trypsin inhibitor (Kunitz) family. Carlsberg Res. Commun. 48, 91-94 (1983)

9. HejgaArd, J, S. K. Rasmussen, A. Brandt \& I. SVENDSEN: Sequence homology between barley endosperm protein $Z$ and protease inhibitors of the $a_{1}$-antitrypsin family. FEBS Lett. 180, 89-94 (1985)

10. Houmard, J. \& G. R. Drapeau: Staphylococcal protease: A proteolytic enzyme specific for glutamoyl bonds. Proc. Natl. Acad. Sci. USA, 69, 3506-3509 (1972)

11. Johansen, J. T., C. Overballe-Petersen, B. MARTIN, V. HASEMANN \& I. SVENDSEN: The complete amino acid sequence of copper, zinc superoxidedismutase from Saccharomyces cereviciae. Carlsberg Res. Commun. 44, 201-217 (1979) 
12. Kim, S. -H., S. HaRa, S. Hasa, T. Ikenaka, H. Toda, K. Kitamura \& N. Kaizuma: Comparative study on amino acid sequences of Kunitz-type soybean trypsin inhibitors $\mathrm{Ti}^{\mathrm{a}}, \mathrm{Ti}^{\mathrm{b}}$ and $\mathrm{Ti}^{\mathrm{c}}$. $\mathrm{J}$. Biochem. (Japan) 98, 435-448 (1985)

13. KOIDE, T. \& T. IKENAKA: Studies on soybean tryp$\sin$ inhibitors. 3. Amino acid sequence of the carboxyl-terminal region and the complete aminoacict sequence of soybean trypsin inhibitor (Kunitz). Eur. J. Biochem. 32, 417-431 (1973)

14. KREIS, M., B. G. Forde, S. RahmaN, B. J. Miflin \& P. R. SHEWRY: Molecular evolution of the seed storage proteins of barley, rye and wheat. J. Mol. Biol. 183, 499-502 (1985)

15. LASKOWSKI, M., JR., I. Kato, T. R. LeaRY, J. SCHRODE \& R. W. SEALOCK: Evolution of specificity of protein proteinase inhibitors. In Proteinase Inhibitors - Bayer symposium V (Fritz, H., H. Tschesche, L. J. Green and E. Truscheit, eds. ) pp 597-611 (Springer Verlag) (1974)

16. Maeda, K., S. Kakabayashi \& H. Matsubara: Complete amino acid sequence of an $\alpha$-amylase inhibitor in wheat kernel (0. 19-inhibitor). Biochim. Biophys. Acta 828, 213-221 (1985)

17. Mahoney, W.C., M.A. Hermodson, B. Jones, D. D. Powers, R. S. Corfman \& G. R. ReECK: Amino acid sequence and secondary structural analysis of the corn inhibitor of trypsin and activated Hageman factor. J. Biol. Chem. 259, 8412-8416 (1984)

18. Mahoney, W. C., P. K. Smith \& M. A. HermodSON: Fragmentation of proteins with iodosobenzoic acid: Chemical mechanism and identification of o-iodosobenzoic acid and a reactive contaminant that modifies tyrosyl residues. Biochemistry 20, 443-448 (1981)

19. Mundy, J., I. SVendSEn \& J. HejgaARd: Barley a-amylase/subtilisin inhibitor. I. Isolation and characterization. Carlsberg Res. Commun. 48, 81-90 (1983)

20. Mundy. J., J. HejgaARd \& I. Svendsen: Characterization of a bifunctional wheat inhibitor of endogenous $\alpha$-amylase and subtilisin. FEBS Lett. 167, 210-214 (1984)

21. MUNDY, J. \& J. Rogers: A probable amylase/protease inhibitor expressed at high levels in barley aleurone cells: Comparison to the barley amylase subtilisin inhibitor (submitted to J. Biol. Chem. )

22. ODANI, S., T. KoIDE\& T. ONO: Sequence homology between barley trypsin inhibitor and wheat $\alpha$-amylase inhibitors. FEBS Lett. 141, 279-282 (1982)

23. OdANI, S., T. Kolde \& T. ONO: The complete amino acid sequence of barley trypsin inhibitor. $\mathrm{J}$. Biol. Chem. 258, 7998-8003 (1983)

24. Odani, S., T. Kolde \& T. ONO: A possible evolutionary relationship between plant trypsin inhibitor, $\alpha$-amylase inhibitor, and mammalian pancreatic secretory trypsin inhibitor (Kazal). J. Biochem. (Japan) 93, 1701-1704 (1983)

25. Odani, S., T. Koide, T. OnO \& K. Ohnishi: Structural relationship between barley (Hordeum vulgare) trypsin inhibitor and castor-bean (Ricinus communis) storage protein. Biochem. J. 213, 543545 (1983)

26. SVendSEn, I., B. MaRTin \& I. JonASSEN: Characteristics of Hiproly barley III. Amino acid sequences of two lysine-rich proteins. Carlsberg Res. Commun. 45, 79-85 (1980)

27. SVENDSEn, I., S. I. HANSEN, J. Holm \& J. Ly NGBYE: The complete amino acid sequence of the folatebinding protein from cow's milk. Carlsberg Res. Commun 49, 123-131 (1984)

28. Svensson, B., K. Asano, I. Jonassen, F. M. PoulSEN, J. MUNDY \& I. SVENDSEN: Barley seed protein with $M, 10.000$ showing homology with an $\alpha$-amylase inhibitor from Indian finger millet. Isolation and characterization. Carlsberg Res. Commun. 51, .... (1986)

29. SweEt, R. M., H. T. WRight, J. JANin, C. H. ChOTHIA \& D. M. BLOW: Crystal structure of the complex of porcine trypsin with soybean trypsin inhibitor (Kunitz) at 2. 6- $\dot{A}$ resolution. Biochemistry 13, 4212-4228 (1974)

30. Yamamoto, M., S. Hara \& T. IKenaKa: Amino acid sequences of two trypsin inhibitors from winged bean seeds (Psophocarpus tetra gonolobus (L) DC. ). J. Biochem. (Japan) 94, 849-863 (1983)

31. Yoshikawa, M., T. Iwasaki, M. FuJil \& M. OoGAKI: Isolation and some properties of a subtilisin inhibitor from barley. J. Biochem. (Japan) 79, 765-773 (1976) 